Dehydration, Micellization, and Phase Separation of Thermosensitive Polyoxazoline Star Block Copolymers in Aqueous Solution

Sezonenko, Tetiana

2019-02-12

Sezonenko , T , Qiu , X-P , Winnik , F M \& Sato , T 2019 , ' Dehydration, Micellization, and Phase Separation of Thermosensitive Polyoxazoline Star Block Copolymers in Aqueous Solution ' , Macromolecules , vol. 52 , no. 3 , pp. 935-944 . https://doi.org/10.1021/acs.macromol.8b02528

http://hdl.handle.net/10138/311472

https://doi.org/10.1021/acs.macromol.8b02528

cc_by_nc

acceptedVersion

Downloaded from Helda, University of Helsinki institutional repository.

This is an electronic reprint of the original article.

This reprint may differ from the original in pagination and typographic detail.

Please cite the original version. 


\title{
Dehydration, Micellization, and Phase Separation of Thermosensitive Polyoxazoline Star Block-Copolymers in Aqueous Solution
}

Tetiana Sezonenko, ${ }^{1}$ Xing-Ping Qiu, ${ }^{2}$ Françoise M. Winnik, ${ }^{3}$ and Takahiro Sato ${ }^{1}$

${ }^{1}$ Department of Macromolecular Science, Osaka University, 1-1 Machikaneyama-cho, Toyonaka 560-0043, Japan

${ }^{2}$ Faculty of Pharmacy, Department of Chemistry, University of Montreal, CP 6128 Succursale Centre Ville Montreal, Quebec, Canada H3C 3J7

${ }^{3}$ Department of Chemistry, University of Helsinki, P.O. Box 55 (A.I. Virtasen aukio1) FI-00014 Helsinki, Finland

\begin{abstract}
:
Suitably end-functionalized diblock copolymers (2-isopropyl-2-oxazoline)- $b$ (2-ethyl-2-oxazoline) (PIPOZ- $b$-PEOZ) were linked to a tetrafunctional core in order to synthesize two isomeric thermosensitive 4-arm star block polymers which have the PIPOZ block near the core, core-(PIPOZ- $b$-PEOZ) $)_{4}$, or near the outer surface the star polymer, core-(PEOZ- $b$-PIPOZ) 4 . The solution properties of the star copolymers in water were monitored by turbidimetry, microcalorimetry, and small-angle X-ray scattering (SAXS). The dehydration and cloud-point temperatures of both core-(PIPOZ- $b$-PEOZ) 4 and core-(PEOZ- $b$-PIPOZ) 4 in water are in the vicinity of $50{ }^{\circ} \mathrm{C}$. Above this temperature, core-(PIPOZ- $b$-PEOZ) 4 forms star-like aggregates, whereas core-(PEOZ-b-PIPOZ) $)_{4}$ remains isolated, with no sign of aggregation. These results demonstrate the importance of chain architecture on the association of thermosensitive tetra-arm star block copolymers in water above the solutions phase transition temperature.
\end{abstract}


Key words: thermosensitive polymer, star block copolymer, dehydration, micelle, phase separation, small angle X-ray scattering

\section{INTRODUCTION}

Star polymers are versatile building blocks in the preparation of functional materials. ${ }^{1}$ The functionality of the material is amplified by end-modification of the arms. ${ }^{1,3}$ In the case of core-modified star polymers, the arms stabilize, protect, or modulate the inner functionality. ${ }^{1,2}$. Stimuli-responsive star block copolymers are useful in various biotechnological applications, since their conformation and self-association can be controlled through changes in temperature ${ }^{2,4-7} \mathrm{pH}^{6,8-10}$ light, $^{2,11}$ or ionic strength ${ }^{9,12}$. There have been few studies so far on the effects of the star copolymers architecture on their conformation and intermolecular interactions in solution, although they are of fundamental importance and should be known in order to use the unique features of star copolymer most effectively.

Takahashi et al. ${ }^{13}$ have reported the effect of temperature on the dehydration, self-association, and phase separation behavior in water of diblock copolymers containing a poly(2-ethyl-2-oxazoline) (PEOZ) and a poly(2-isopropyl-2-oxazoline) (PIPOZ) block. Both PIPOZ and PEOZ are soluble in water below ca. $45^{\circ} \mathrm{C}$. The PIPOZ chains dehydrate between 45 and $55^{\circ} \mathrm{C}$, while PEOZ remains soluble in water, hence PEOZ- $b$-PIPOZ copolymers are amphiphilic in this temperature range. Above $55^{\circ} \mathrm{C}$, both PIPOZ and PEOZ are dehydrated and insoluble in water. It was observed experimentally that at $50{ }^{\circ} \mathrm{C}$ PEOZ- $b$-PIPOZ aggregation occurs with concomitant macroscopic liquid-liquid phase separation, whereas at $70{ }^{\circ} \mathrm{C}$ phase separation occurs without macroscopic phase separation.

Using PEOZ- $b$-PIPOZ diblock copolymers, we prepare via click coupling two isomeric tetra-arm star copolymers, [core-(PIPOZ- $b$-PEOZ) 4 ], in which the PIPOZ blocks are linked directly to the core, and [core-(PEOZ- $b$-PIPOZ) 4 , in which the PEOZ block is linked to the core (cf. Scheme 1). These two star block copolymers were utilized to investigate the architecture dependences of the micellar structure as well as the dehydration and phase 
separation behavior of the star copolymers upon heating. The micellar structure and dehydration behavior were investigated by small angle X-ray scattering (SAXS) and high-sensitivity differential scanning calorimetry (HS-DSC), respectively.

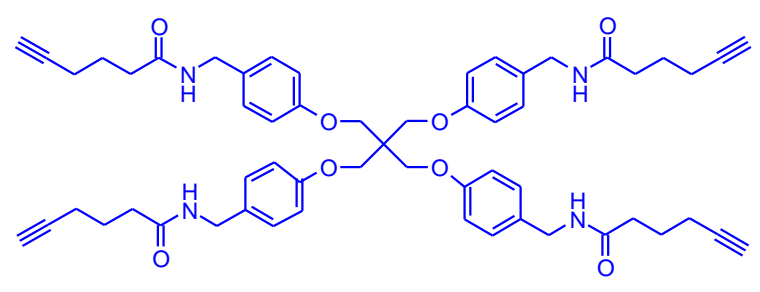

core-4-yne

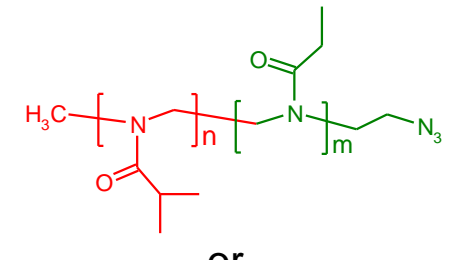

$+$

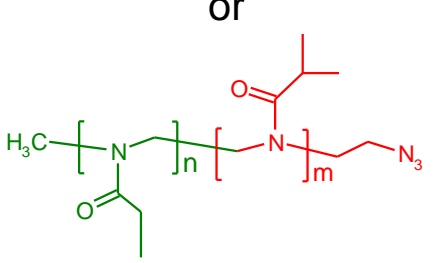

$\mathrm{Cu}(\mathrm{I}) \downarrow \mathrm{DMF}$

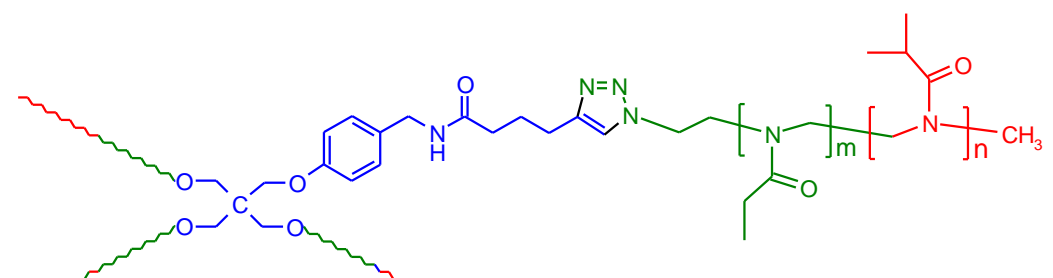

core-(PEOZ-b-PIPOZ) ${ }_{4}$

or

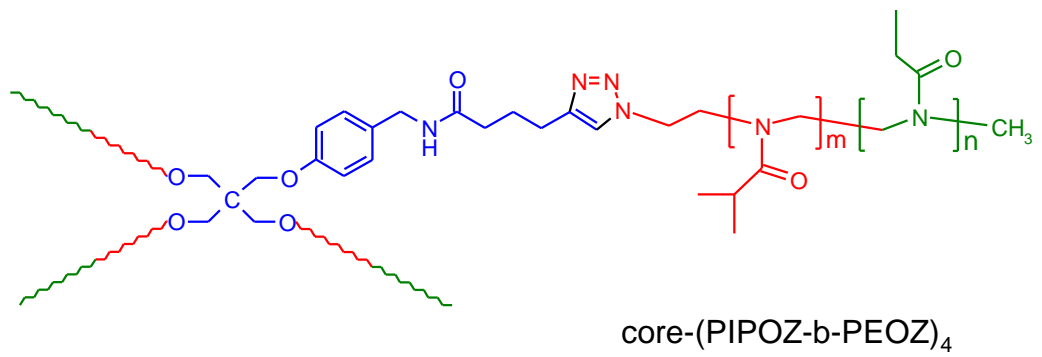

Scheme 1. Synthesis of of core-(PEOZ- $b$-PIPOZ) $)_{4}$ and core-(PIPOZ- $b$-PEOZ) $)_{4}$ starting from the tetrafunctional moiety core-4-yne.

\section{EXPERIMENTAL SECTION}

Materials. All chemicals were purchased from Sigma-Aldrich Chemical Co. and used as received unless specified otherwise. 2-Isopropyl-2-oxazoline was synthesized from isobutyronitrile and 2-aminoethanol according to the synthetic protocol of Huber and 
Jordan. ${ }^{14}$ The monomers, 2-isopropyl-2-oxazoline (IPOZ) and 2-ethyl-2-oxazoline (EOZ), were purified by vacuum distillation over calcium hydride. Dimethylformamide (DMF) and acetonitrile $(\mathrm{AcCN})$ were purified by a solvent purification system with two columns packed with activated alumina provided by Innovative Technology Inc. Water was deionized using a Millipore MilliQ system.

Instrumentation, ${ }^{1} \mathrm{H}$ NMR spectra were recorded on a Bruker AMX-400 (400 MHz) spectrometer using chloroform-D $\left(\mathrm{CDCl}_{3}\right)$ as the solvent. The molecular weight and its distribution (PDI) of the polymers were measured with a GPC-MALLS system consisting of an Agilent 1100 isocratic pump, a set of TSK-gel a-M (particle size $13 \mu$, exclusion limit $1 \times$ $10^{7} \mathrm{Da}$ for polystyrene in DMF) and a TSK-gel a-3000 (particle size $7 \mu$, exclusion limit $1 \times$ $10^{5}$ Da for polystyrene in DMF) (Tosoh Biosep) columns, a Dawn EOS multi-angle laser light scattering detector $\lambda=690 \mathrm{~nm}$ (Wyatt Technology Co.) and an Optilab DSP interferometric refractometer $\lambda=690 \mathrm{~nm}$ (Wyatt Technology Co.) under the following conditions: injection volume, $100 \mu \mathrm{L}$; flow rate, $0.3 \mathrm{~mL} / \mathrm{min}$; eluent, DMF; temperature, $40{ }^{\circ} \mathrm{C}$. The specific refractive index increment $\partial n / \partial c$ of the diblock copolymer in DMF was calculated by $\partial n / \partial c=$ $w_{1}(\partial n / \partial c)_{1}+w_{2}(\partial n / \partial c)_{2}$ with $w_{1}$ and $w_{2}$ denoting the weight fraction of PIPOZ $\left[(\partial n / \partial c)_{1}=\right.$ $0.084 \mathrm{~mL} / \mathrm{g}]$ and PEOZ $\left[(\partial n / \partial c)_{2}=0.078 \mathrm{~mL} / \mathrm{g}\right]$ blocks, respectively.

Synthesis of the PIPOZ-b-PEOZ-N 3 diblock copolymer. The diblock copolymer PIPOZ- $b$-PEOZ-N 3 was synthesized by sequential cationic ring opening polymerization (CROP) of 2-isopropyl-2-oxazoline and 2-ethyl-2-oxazoline initiated by methyltrifluoromethanesulfonate in acetonitrile at $70{ }^{\circ} \mathrm{C} .{ }^{15}$ A flame-dried flask equipped with a $\mathrm{N}_{2}$-filled condenser and a rubber stopper was charged with dry acetonitrile $(20 \mathrm{~mL})$. The first monomer, 2-isopropyl-2-oxazoline $(2.5 \mathrm{~mL}, 22.0 \mathrm{mmol})$, and the initiator, methyl triflate $(50 \mu \mathrm{L}, 0.44$ mmol) were added in sequence at room temperature via $\mathrm{N}_{2}$-filled syringes. The flask was immersed in an oil bath pre-heated to $70{ }^{\circ} \mathrm{C}$. The polymerization was conducted at $70{ }^{\circ} \mathrm{C}$ for 3 days until monomer conversion reached $\sim 95 \%$, as determined by ${ }^{1} \mathrm{H}$ NMR spectroscopy. 
Then, the second monomer, 2-ethyl-2-oxazoline $(2.5 \mathrm{~mL}, 25.0 \mathrm{mmol})$ was added and the polymerization was continued for another 2 days at the same temperature until the overall monomer conversion reached $\sim 90 \%$. Sodium nitride $\left(\mathrm{NaN}_{3}, 0.3 \mathrm{~g}, 4.4 \mathrm{mmol}\right)$ was added to quench the terminal oxazolinium groups. The termination reaction was conducted at $60{ }^{\circ} \mathrm{C}$ for 6 hours. Afterwards, the polymerization solution was cooled to room temperature and diluted with water to $100 \mathrm{~mL}$. The resulting solution was dialyzed against deionized water for 3 days. The purified polymer was recovered by freeze-drying. Yield $4.0 \mathrm{~g}, 80 \% .{ }^{1} \mathrm{H}$ NMR $\left(\mathrm{CDCl}_{3}, \delta\right)$ ppm: $1.10\left(\mathrm{~s},-\mathrm{CH}\left(\mathrm{CH}_{3}\right)_{2}\right), 2.32$ and $2.42\left(\mathrm{~d},-\mathrm{CH}_{2} \mathrm{CH}_{3}\right), 2.69$ and $2.91(\mathrm{~d}$, $\left.-\mathrm{CH}\left(\mathrm{CH}_{3}\right)_{2}\right), 3.45\left(\mathrm{~s},-\mathrm{NCH}_{2} \mathrm{CH}_{2}-\right)$; cf. Figure $\mathrm{S} 1$ in the Supporting Information.

Synthesis of the PEOZ- $b$-PIPOZ-N 3 Diblock Copolymer. The diblock copolymer PEOZ- $b$-PIPOZ-N ${ }_{3}$ was synthesized by sequential CROP of 2-ethyl-2-oxazoline and 2-isopropyl-2-oxazoline as described above, except that 2-ethyl-2-oxazoline was polymerized first, followed by addition of 2-isopropyl-2-oxazoline $(2.5 \mathrm{~mL}, 22.0 \mathrm{mmol})$; Yield $4.0 \mathrm{~g}, 80 \%$. ${ }^{1} \mathrm{H} \mathrm{NMR}\left(\mathrm{CDCl}_{3}, \delta\right)$ ppm: $1.10\left(\mathrm{~s},-\mathrm{CH}\left(\mathrm{CH}_{3}\right)_{2}\right), 2.32$ and $2.42\left(\mathrm{~d},-\mathrm{CH}_{2} \mathrm{CH}_{3}\right), 2.69$ and $2.91(\mathrm{~d}$, $\left.-\mathrm{CH}\left(\mathrm{CH}_{3}\right)_{2}\right), 3.45\left(\mathrm{~s},-\mathrm{NCH}_{2} \mathrm{CH}_{2}\right.$ ) ; cf. Figure $\mathrm{S} 2$ in the Supporting Information.

Synthesis of core-(PEOZ-b-PIPOZ) 4 Star Block Copolymer. Core-4-yne (19.6 mg, 0.02 mmol, 1 equiv.) and PIPOZ- $b-$ PEOZ-N $_{3}$ (1.2 g, 0.16 mmol, 8 equiv.) were dissolved in dry DMF $(15 \mathrm{~mL})$. After degassing with $N_{2}$ for $30 \mathrm{~min}, \quad N, \quad N, \quad N^{\prime}, \quad N^{\prime \prime}$, $N "$-pentamethyldiethylenetriamine (PMDETA, $17.3 \mathrm{mg}, 0.1 \mathrm{mmol}, 5$ equiv.) and cuprous bromide ( $\mathrm{CuBr}, 14.3 \mathrm{mg}, 0.1 \mathrm{mmol}, 5$ equiv.) were added. The mixture was stirred at room temperature for 3 days. Afterwards, $15 \mathrm{~mL}$ of water was added and the solution was dialysed against deionized water for 2 days with a regenerated cellulose membrane (MWCO of 3.5 $\mathrm{kDa}$ ). The solution was concentrated and purified by ultrafiltration using a Millipore $76 \mathrm{~mm}$ ultracel membrane (MWCO of $10 \mathrm{kDa}$ ) to remove unreacted PIPOZ- $b$-PEOZ-N 3 . The retentate was freeze-dried to obtain the star polymer core-(PEOZ- $b$-PIPOZ) 4 as a white solid. Yield $0.5 \mathrm{~g}, 80 \% .{ }^{1} \mathrm{H} \mathrm{NMR}\left(\mathrm{CDCl}_{3}, \delta\right) \mathrm{ppm}: 1.10\left(\mathrm{~s},-\mathrm{CH}\left(\mathrm{CH}_{3}\right)_{2}\right), 2.32$ and $2.42\left(\mathrm{~d},-\mathrm{CH}_{2} \mathrm{CH}_{3}\right)$, 
2.69 and 2.91 (d, $\left.-\mathrm{CH}\left(\mathrm{CH}_{3}\right)_{2}\right), 3.45$ (s, $\left.-\mathrm{NCH}_{2} \mathrm{CH}_{2}-\right), 4.30$ and 4.34 (d, $\left.\mathrm{Ar}-\mathrm{CH}_{2}-\mathrm{NH}-\right), 6.84$ (s, Ar- $H)$, and $6.25(\mathrm{~s}, \mathrm{Ar}-H)$.

Synthesis of core-(PIPOZ-b-PEOZ) 4 Star Block Copolymer. The star block copolymer core-(PIPOZ- $b$-PEOZ) $)_{4}$ was synthesized in the same way as the star block copolymer core-(PEOZ- $b$-PIPOZ) 4 , starting from core-4-yne (19.6 mg, $0.02 \mathrm{mmol}, 1$ equiv.) and PEOZ- $b$-PIPOZ-N 3 (1.2 g, 0.16 mmol, 8 equiv).

High-Sensitivity Differential Scanning Calorimetry (HS-DSC). HS-DSC measurements were performed on a VP-DSC microcalorimeter (MicroCal Inc.) at an external pressure of ca. $250 \mathrm{kPa}$. The cell volume is $0.520 \mathrm{~mL}$. The polymer concentration was set to $w$ (the polymer weight fraction $)=0.001$, and the heating rate was set at $1.0{ }^{\circ} \mathrm{C} / \mathrm{min}$ in the temperature range $10-80{ }^{\circ} \mathrm{C}$. The experimental data were analyzed using the Origin based software supplied by the manufacturer. A cubic connect baseline was subtracted from the data prior to fitting.

Turbidimetry. Turbidities of aqueous star block copolymer solutions (the copolymer weight fraction $w=0.001$ ) were measured by spectrophotometric detection of the changes in turbidity at $\lambda=550 \mathrm{~nm}$ on an Agilent $8453 \mathrm{UV}$-Visible spectroscopy system equipped with an HP 89090A Peltier temperature controller. The heating rate was $0.2{ }^{\circ} \mathrm{C} / \mathrm{min}$.

Phase Separation Observation. Aqueous solutions of core-(PIPOZ- $b-\mathrm{PEOZ})_{4}$ and core-(PEOZ- $b$-PIPOZ) 4 with a polymer weight fraction $w=0.0244$ were placed in stoppered glass test tubes, and kept at 50 and $60{ }^{\circ} \mathrm{C}$ in a thermostated oven and monitored visually at various heating times.

\section{Preparation of solutions for SAXS measurements}

Small-Angle X-Ray Scattering (SAXS). SAXS measurements were conducted on aqueous solutions of the core-(PIPOZ- $b$-PEOZ) 4 and core-(PEOZ- $b$-PIPOZ) $)_{4}$ samples with $w$ $=0.0244$ at $25,40,50,60$, and $70{ }^{\circ} \mathrm{C}$, using the beamline 40B2 at Spring- 8 , Kobe, Japan. The test solutions were placed in capillary tubes. The capillary tubes were placed in a heating 
block set at a constant temperature to ensure rapidly heating. The scattered X-ray intensities were measured using an imaging plate detector $3 \mathrm{~min}$ after the T-jump. A new test solution was used for each T-jump experiment to different temperatures.

The SAXS excess Rayleigh ratio $R_{\mathrm{X}, \theta}$ at the scattering angle $\theta$ and the optical constant $K_{\mathrm{e}}$ of SAXS were calculated by ${ }^{16,17}$

$$
R_{\mathrm{X}, \theta}=F\left(\frac{I_{\theta, \text { soln }}}{I_{\text {mon,soln }}}-\frac{I_{\theta, \text { solv }}}{I_{\text {mon,solv }}}\right), \quad K_{\mathrm{e}}=N_{\mathrm{A}} a_{\mathrm{e}}^{2} \gamma_{\mathrm{av}}^{2}
$$

Here, $F$ is the instrument constant, $I_{\theta, \text { soln }}\left(I_{\theta, \text { solv }}\right)$ and $I_{\text {mon,soln }}\left(I_{\text {mon,solv }}\right)$ are the scattering intensity at the scattering angle $\theta$ and the monitor value of the incident SAXS intensity, respectively, of the solution (of the solvent), $N_{\mathrm{A}}$ is the Avogadro constant, $a_{\mathrm{e}}$ is the electron radius $\left(2.8 \times 10^{-13} \mathrm{~cm}\right)$, and $\gamma_{\mathrm{av}}$ is the average SAXS contrast factor of the copolymer. The value of $\gamma_{\mathrm{av}}$ for the copolymer in water was calculated by

$$
\gamma_{\mathrm{av}}=\frac{M_{\mathrm{w}, \mathrm{PIPOZ}} \gamma_{\mathrm{IPOZ}}+M_{\mathrm{w}, \mathrm{PEOZ}} \gamma_{\mathrm{EOZ}}}{M_{\mathrm{w}, \mathrm{PIPOZ}}+M_{\mathrm{w}, \mathrm{PEOZ}}}
$$

with the molar masses $M_{\mathrm{wP}, \mathrm{IPOZ}}$ and $M_{\mathrm{w}, \mathrm{PEOZ}}$, as well as the contrast factors for IPOZ and EOZ monomer units given by

$$
\gamma_{\mathrm{IPOZ}}=\frac{n_{\mathrm{e}, \mathrm{IPOZ}}}{M_{0, \mathrm{IPOZ}}}-\frac{\bar{v}_{\mathrm{IPOZ}}}{v_{\text {solv }}} \frac{n_{\mathrm{e}, \mathrm{H}_{2} \mathrm{O}}}{M_{\mathrm{H}_{2} \mathrm{O}}}, \gamma_{\mathrm{EOZ}}=\frac{n_{\mathrm{e}, \mathrm{EOZ}}}{M_{0, \mathrm{EOZ}}}-\frac{\bar{v}_{\mathrm{EOZ}}}{v_{\text {solv }}} \frac{n_{\mathrm{e}, \mathrm{H}_{2} \mathrm{O}}}{M_{0, \mathrm{H}_{2} \mathrm{O}}}
$$

where $n_{\mathrm{e}, i}$ and $M_{0, i}\left(i=\mathrm{IPOZ}, \mathrm{EOZ}\right.$, and $\left.\mathrm{H}_{2} \mathrm{O}\right)$ are numbers of electrons and molar masses of $i$, respectively, $\overline{v_{i}}$ is the partial specific volume of the monomer unit $i$ (= IPOZ and EOZ), and $v_{\text {solv }}$ is the specific volume of water. By density measurements of the copolymer samples, the partial specific volumes were determined to be $\bar{v}_{\mathrm{IPOZ}}=0.892 \mathrm{~cm}^{3} / \mathrm{g}$ and $\bar{v}_{\mathrm{EOZ}}=0.884$ $\mathrm{cm}^{3} / \mathrm{g}\left(\gamma_{\mathrm{IPOZ}}=0.0531 \mathrm{~mol} / \mathrm{g} ; \gamma_{\mathrm{EOZ}}=0.0543 \mathrm{~mol} / \mathrm{g}\right)$. Temperature dependences of $\gamma_{\mathrm{POZ}}$ and

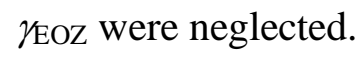

Neglecting the inter-particle interference effect and the dispersity in the copolymer composition, the scattering function can be written as: 


$$
R_{\mathrm{X}, \theta} / K_{\mathrm{e}} c=M_{\mathrm{w}} P_{\mathrm{z}}(k)
$$

where $c$ is the copolymer mass concentration, $M_{\mathrm{w}}$ is the weight average molar mass, and $P_{\mathrm{z}}(k)$ is the z-average particle scattering function. The instrument constant $F$ in eq 1 was determined so as for the low angle $R_{\mathrm{X}, \theta} d K_{\mathrm{e}} c$ for the aqueous core-(PIPOZ- $b$-PEOZ) $)_{4}$ at $25{ }^{\circ} \mathrm{C}$ to agree with $M_{\mathrm{w}, 1}\left(=2.42 \times 10^{4} \mathrm{~g} / \mathrm{mol}\right)$ of the copolymer, determined by SEC-MALS (see Table 1 below).

\section{RESULTS AND DISCUSSION}

Synthesis of the Star Block Copolymers. The star copolymers were prepared by copper-catalyzed click coupling in DMF of a tetra-propargylated moiety (core-4-yne) to either PEOZ- $b$-PIPOZ-N 3 or PIPOZ- $b$-PEOZ-N ${ }_{3}$, which were obtained by methyl trifluoromethane catalyzed sequential CROP polymerization of IPOZ and EOZ, or vice-versa (see experimental section and supporting data for the complete characterization of the copolymers). To ensure complete substitution of the core, the copolymers were added in a 2:1 molar ratio with respect to the alkyne groups of the core (Scheme 1). The mixtures recovered at the end of the coupling reaction were purified by extensive ultracentrifugation with a membrane permeable to the diblock copolymers, but not the tetra-arm stars. The purity of the recovered star copolymers was ascertained by gel permeation chromatography (see GPC scans in Figure S3). In Table 1, we give the composition and molar mass of the diblock copolymers and the tetra-arm star copolymers are presented in Table 1.

Table 1. Molecular characteristics of precursor PIPOZ- $b$-PEOZ samples and star block copolymer samples synthesized.

\begin{tabular}{ccccccc}
\hline polymer & $x_{\text {IPOZ }^{\mathrm{a}}}$ & $M_{\mathrm{n}, 1} / 10^{3 \mathrm{~b}}$ & $M_{\mathrm{w}, 1} / M_{\mathrm{n}, 1}{ }^{\mathrm{c}}$ & $\begin{array}{c}M_{\mathrm{w}, 1} / 10^{3 \mathrm{~d}} \\
\left(M_{\mathrm{w}, 1} / 10^{3 \mathrm{e}}\right)\end{array}$ & $\begin{array}{c}N_{\text {0n,PIPOZ }}{ }^{\mathrm{f}} \\
\left(N_{0 \mathrm{w}, \mathrm{PIOOZ}}{ }^{\mathrm{g}}\right)\end{array}$ & $\begin{array}{c}N_{\text {0n,PEOZ }}{ }^{\mathrm{f}} \\
\left(N_{0 \mathrm{w}, \mathrm{PEOZ}^{\mathrm{g}}}\right)\end{array}$ \\
\hline PEOZ-b-PIPOZ-N N $_{3}$ & 0.585 & 6.5 & 1.14 & $\begin{array}{c}7.4 \\
(7.4)\end{array}$ & $\begin{array}{c}35^{\mathrm{d}} \\
\left(40^{\mathrm{e}}\right)\end{array}$ & $\begin{array}{c}25^{\mathrm{d}} \\
\left(29^{\mathrm{e}}\right)\end{array}$
\end{tabular}




\begin{tabular}{|c|c|c|c|c|c|c|}
\hline core-(PIPOZ- $b$-PEOZ) $)_{4}$ & & 27 & 1.03 & $\begin{array}{c}28 \\
(24)\end{array}$ & $\begin{array}{c}128^{\mathrm{d}} \\
\left(132^{\mathrm{e}}\right)\end{array}$ & $\begin{array}{c}91^{\mathrm{d}} \\
\left(94^{\mathrm{e}}\right)\end{array}$ \\
\hline PIPOZ- $b$-PEOZ-N 3 & 0.42 & 7.5 & 1.05 & $\begin{array}{c}7.9 \\
(7.9)\end{array}$ & $\begin{array}{c}30^{\mathrm{d}} \\
\left(31.5^{\mathrm{e}}\right)\end{array}$ & $\begin{array}{c}41^{\mathrm{d}} \\
\left(43.5^{\mathrm{e}}\right)\end{array}$ \\
\hline core-(PEOZ- $b$-PIPOZ) $)_{4}$ & & 31 & 1.02 & $\begin{array}{c}32 \\
(31)\end{array}$ & $\begin{array}{c}121^{\mathrm{d}} \\
\left(124^{\mathrm{e}}\right)\end{array}$ & $\begin{array}{c}167^{\mathrm{d}} \\
\left(171^{\mathrm{e}}\right)\end{array}$ \\
\hline
\end{tabular}

${ }^{a}$ Mole fraction of IPOZ in the copolymer measured by ${ }^{1} \mathrm{H}$ NMR. ${ }^{b}$ Number average molar mass of the copolymer in units of $\mathrm{g} / \mathrm{mol}$ measured by ${ }^{1} \mathrm{H}$ NMR. ${ }^{c}$ Dispersity index measured by SEC-MALS. ${ }^{\mathrm{d}}$ Weight average molar mass calculated from $M_{\mathrm{n}, 1}$ and $M_{\mathrm{w}, 1} / M_{\mathrm{n}, 1}$ in the third and fourth columns. ${ }^{\mathrm{e}}$ Weight average molar mass measured by SEC-MALS. ${ }^{\mathrm{f}}$ Number average degree of polymerization for the PIPOZ and PEOZ blocks. ${ }^{\mathrm{g}}$ Weight average degree of polymerization of the PIPOZ and PEOZ blocks.

The ${ }^{1} \mathrm{H}$ NMR spectrum of core-(PIPOZ- $b$-PEOZ) 4 in $\mathrm{CDCl}_{3}$ (Figure 1) presents signals due to the resonances of protons of the core at 4.30-4.34 ppm (benzyl protons) and 6.84-7.25 ppm (aromatic protons) in addition to the signals due to the copolymers of the arms. The complete substitution of the core indicated by GPC measurements was validated by the relative intensity of the signals due to the protons of the arms and the core and the known composition of the diblock copolymers. The molecular formulae of the two star copolymers are core-(PIPOZ $35-b$ - $\left.\mathrm{PEOZ}_{25}\right)_{4}$ and core-(PEOZ $\left.41-b-\mathrm{PIPOZ}_{30}\right)_{4}$, respectively. Based on the formulae, the $M_{\mathrm{n}}$ of the two star copolymers was calculated to be 26.8 and $30.8 \mathrm{kDa}$, respectively, in good agreement with the values measured by SEC-MALS (Table 1). The ${ }^{1} \mathrm{H}$ NMR spectrum of core-(PEOZ-b-PIPOZ) 4 is shown in Figure S4. 


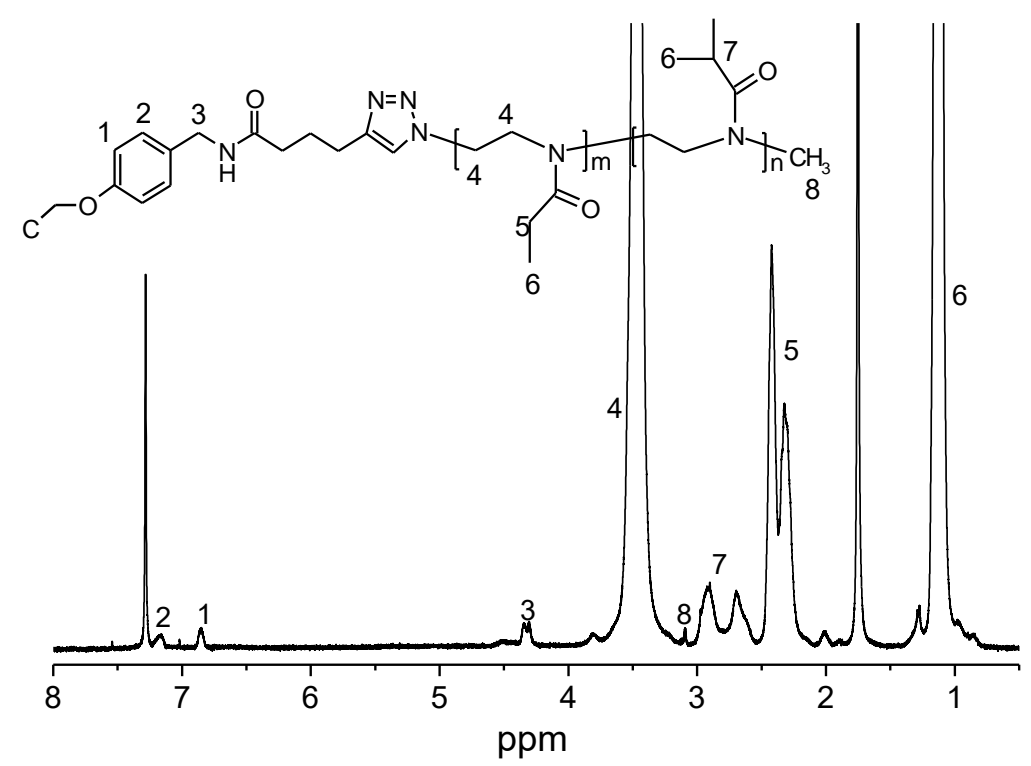

Figure 1. ${ }^{1} \mathrm{H}$ NMR spectrum of core-(PEOZ- $b$-PIPOZ) $)_{4}$ in $\mathrm{CDCl}_{3}$.

HS-DSC Thermograms. The thermograms of aqueous solutions of the two star block copolymers feature a single endotherm (Figure 2) with maxima at $47.0{ }^{\circ} \mathrm{C}$ and $50{ }^{\circ} \mathrm{C}$ for core-(PIPOZ- $b$-PEOZ) 4 and core-(PEOZ- $b$-PIPOZ) $)_{4}$, respectively. The mole fraction of IPOZ is slightly higher in core-(PEOZ- $b$-PIPOZ) 4 , compared to core-(PIPOZ- $b$-PEOZ), which may account for the difference in the two $\mathrm{T}_{\mathrm{m}}$ values. Also, the full width at half maximum of the endotherm recorded for aqueous core-(PEOZ- $b$-PIPOZ) $)_{4}\left(=7.7{ }^{\circ} \mathrm{C}\right)$ is slightly broader than in the case of core-(PIPOZ- $b$-PEOZ $)_{4}\left(=6.6{ }^{\circ} \mathrm{C}\right)$, indicating that the dehydration temperature difference between the PEOZ and PIPOZ block chains for core-(PEOZ- $b$-PIPOZ) 4 may be slightly larger than that for core-(PIPOZ-b-PEOZ) 4 . The DSC thermograms for aqueous solutions of the two star block copolymers are compared with those for aqueous solutions of the precursor block copolymers in the Supporting Information. Sato-san: I would like to show the DSC of the deblocks in the main text with a short description, or else not mention them alla1 


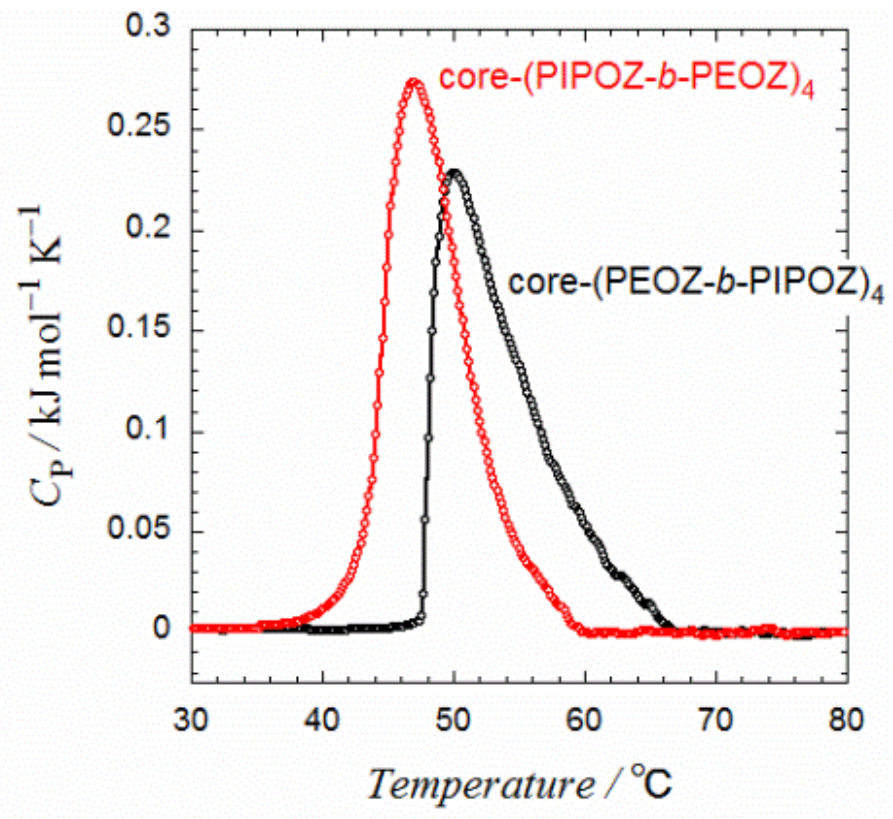

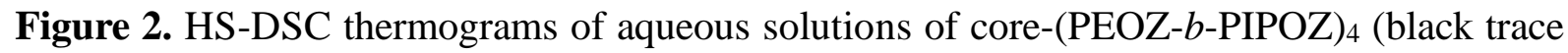
and core-(PIPOZ- $b$-PEOZ) 4 (red trace); polymer concentration: $2.0 \mathrm{~g} / \mathrm{L}$; heating rate: 1.0 ${ }^{\circ} \mathrm{C} / \mathrm{min}$.

Determination of the cloud point of aqueous tetra-arm star copolymers in water. The temperature dependence of the transmittance at $550 \mathrm{~nm}$ of aqueous solutions of the two star block copolymers are presented in Figure 3, together with the transmittance data recorded for the starting diblock copolymers. Sato-san: I suggest we move here the data now in SI. The solutions cloud points, taken as the temperature corresponding to the sharp decrease in solution transmittance, are slightly lower than the temperatures $\mathrm{T}_{\mathrm{m}}$ derived from the endotherms recorded by HS-DSC (Figure 2), as observed in previous studies of aqueous amphiphilic polymer solutions.

Temperature induced liquid/liquid phase separation of aqueous tetra-arm star copolymers in water. When aqueous solutions of core-(PIPOZ- $b$-PEOZ) 4 and core-(PEOZ- $b$-PIPOZ) $)_{4}$ with $w=0.0244$ are heated at 50 and $60{ }^{\circ} \mathrm{C}$ for a few hours, macroscopic phase separation takes place. In Figure 4, we present photographs of aqueous

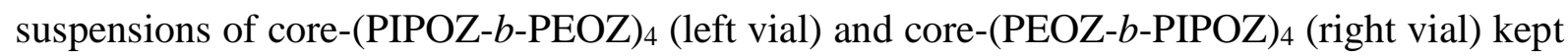


at $50{ }^{\circ} \mathrm{C}$ (top row) and $60{ }^{\circ} \mathrm{C}$ (bottom row) for $240 \mathrm{~min}$. For each temperature, macroscopic phase separation occurs faster in the core-(PEOZ- $b$-PIPOZ) $)_{4}$ sample, compared to the core-(PIPOZ- $b$-PEOZ) 4 sample. As shown in Figure 2, the peak of the DSC thermogram for the aqueous core-(PEOZ- $b$ - PIPOZ) $)_{4}$ is slightly broader, so that the PEOZ block chain in core-(PEOZ- $b$-PIPOZ) 4 should be more hydrophilic than the PEOZ block chain in core-(PIPOZ- $b$-PEOZ) 4 , which may help the coagulation of colloidal concentrated-phase droplets. ${ }^{13,18}$ The sharpness is related usually to the cooperativity of the transition. The sample hydrophobicity affects Tm or Tc. so I would delete the sentence in red above t. Macroscopic phase separation was reported in an earlier study of related PIPOZ- $b$-PEOZ aqueous solutions heated at $50{ }^{\circ} \mathrm{C}$ for $240 \mathrm{~min} .{ }^{13}$ Hence, this characteristic feature of the copolymers is preserved upon linkage to the tetrafunctional core.

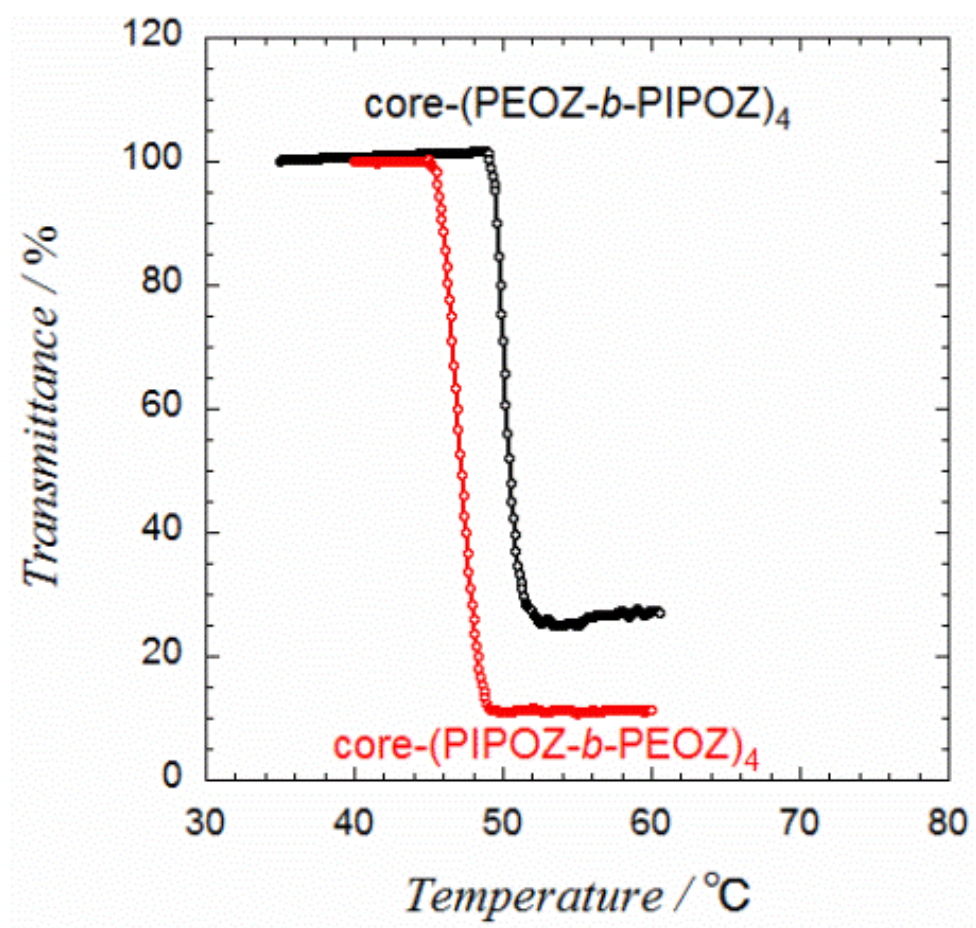

Figure 3. Temperature dependence of the transmittance at $550 \mathrm{~nm}$ of aqueous solutions of core-(PIPOZ- $b$-PEOZ) 4 and core-(PEOZ- $b$-PIPOZ) 4 ; polymer concentration: $1.0 \mathrm{~g} / \mathrm{L}$; heating rate: $0.2{ }^{\circ} \mathrm{C} / \mathrm{min}$. 


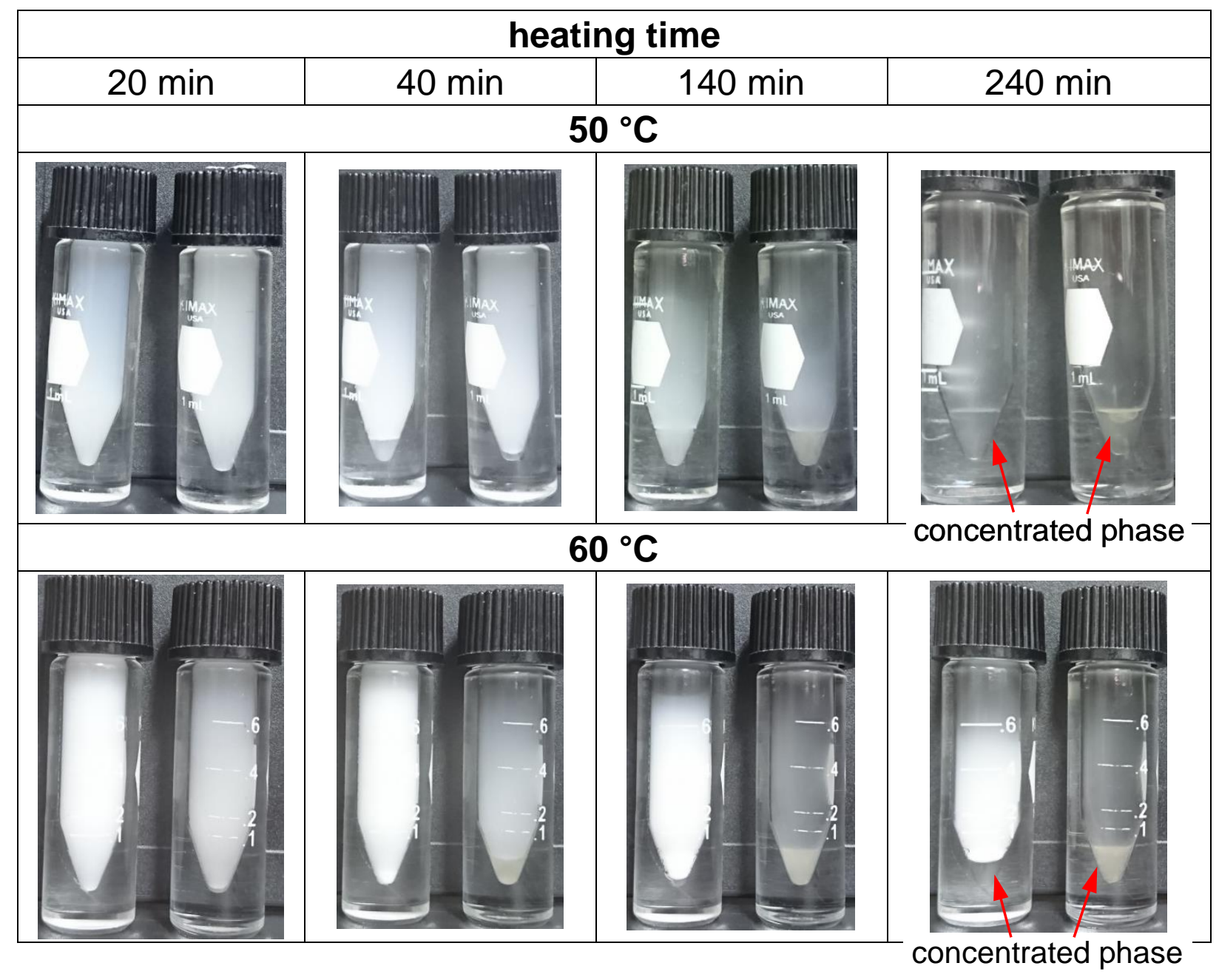

Figure 4. Photographs of phase separating aqueous solutions $(w=0.0244)$ of core-(PIPOZ- $b$-PEOZ) 4 (left vial in each photograph) and core-(PEOZ- $b$-PIPOZ) 4 (right vial in each photograph) heated for prolonged time at $50{ }^{\circ} \mathrm{C}$ (top row) and $60{ }^{\circ} \mathrm{C}$ (bottom row).

SAXS Profiles. Figure 5 shows SAXS profiles recorded for aqueous solutions of core-(PIPOZ- $b$-PEOZ) $)_{4}$ and core-(PEOZ- $b$-PIPOZ) $)_{4}(w=0.0244) 3 \mathrm{~min}$ after a T-jump to different temperatures. After such as short time, the turbid samples show no sign of macroscopic phase separation. In Panel a, the scattering profile for the aqueous core-(PIPOZ- $b$-PEOZ) 4 shows a plateau at $k<0.3 \mathrm{~nm}^{-1}$ at $25{ }^{\circ} \mathrm{C}$, and the plateau value increases at 40 and $50{ }^{\circ} \mathrm{C}$. These plateaus indicate that the solutions contain only a small scattering component, and the aggregation number of the small component slightly increases with increasing temperature up to $50{ }^{\circ} \mathrm{C}$. It is noted that the heat capacity in Figure 2 starts 
increasing for core-(PIPOZ- $b$-PEOZ) 4 above $40{ }^{\circ} \mathrm{C}$, corresponding to the increase of the scattering plateau value. On the other hand, at 60 and $70{ }^{\circ} \mathrm{C}$, the scattering profile shows an upswing in the low $k$ region, a plateau in the intermediate $k$ region $\left(0.2 \mathrm{~nm}^{-1}<k<0.4 \mathrm{~nm}^{-1}\right)$, and a sharp decrease for $k>0.4 \mathrm{~nm}^{-1}$. These profiles indicate that the solutions contain large and small scattering components.
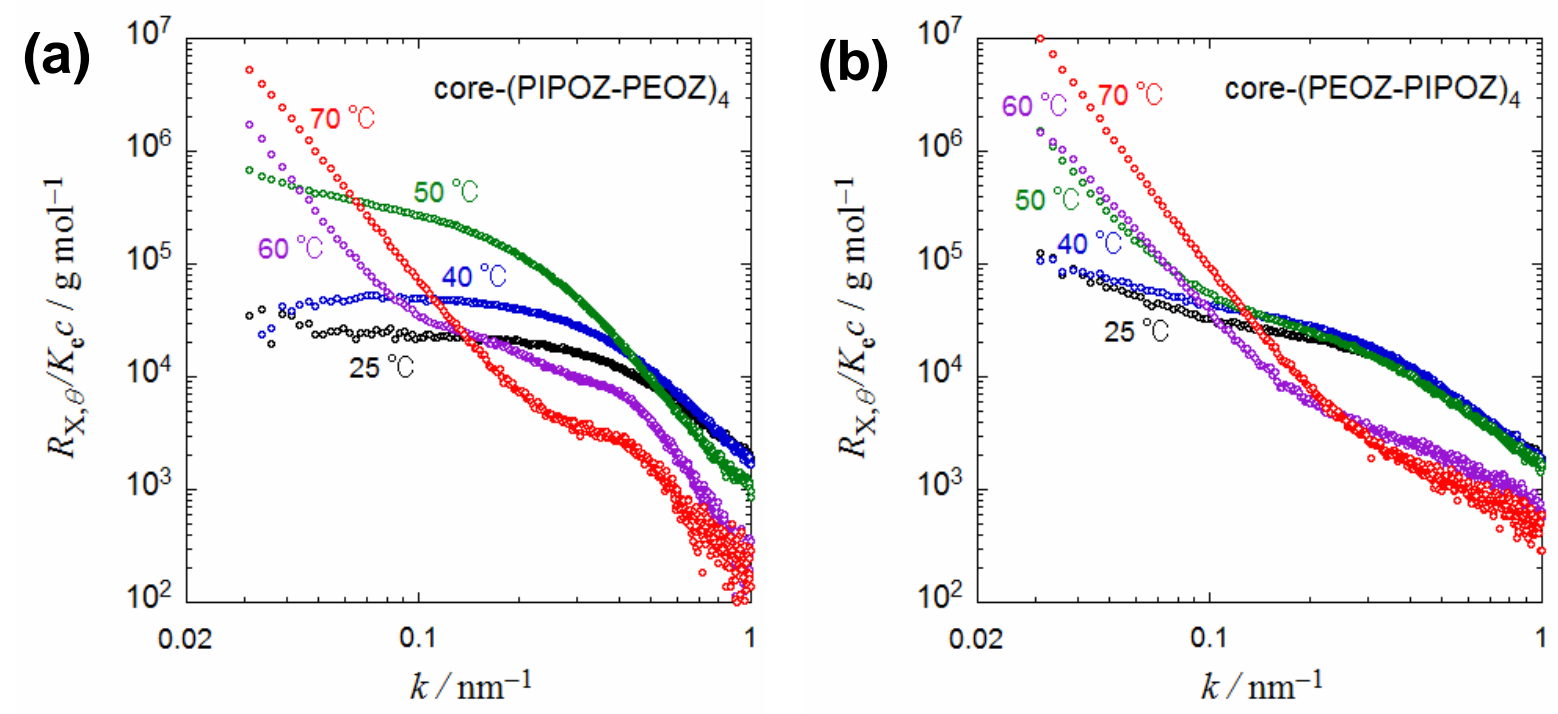

Figure 5. SAXS results for aqueous solutions of (a) core-(PEOZ-b-PIPOZ) 4 and (b) core-(PIPOZ- $b$-PEOZ $)_{4}(w=0.0244)$ at different temperatures.

In Panel $b$ of Figure 5, the scattering profile for the aqueous core-(PEOZ- $b$-PIPOZ) 4 shows a small upswing in the $k$ region lower than $0.1 \mathrm{~nm}^{-1}$ even at $25{ }^{\circ} \mathrm{C}$, and the upswing is enhanced above $50{ }^{\circ} \mathrm{C}$. The scattering intensity decreases in the $k$ region higher than $0.1 \mathrm{~nm}^{-1}$ at 60 and $70{ }^{\circ} \mathrm{C}$. The upswing of the scattering function in the low $k$ region indicates the existence of large aggregates in the solution, and the scattering intensity decrease in the high $k$ region demonstrates the decrease of the main component of a small size. As shown in Figure 2, the dehydration starts around $50{ }^{\circ} \mathrm{C}$ for core-(PEOZ- $b$-PIPOZ) 4 , which corresponds to the scattering profile change. The decay of the scattering intensity at $k>0.5 \mathrm{~nm}^{-1}$ is markedly sharper for core-(PPIOZ- $b$-PEOZ) $)_{4}$ in Panel a than core-(PEOZ- $b$-PIPOZ) $)_{4}$ in Panel b, indicating that the small scattering components of the two star block copolymers takes 
different conformations.

Let us discuss the above scattering profiles more quantitatively. At $25{ }^{\circ} \mathrm{C}$, the dehydration does not take place, neither in the case of PIPOZ nor of PEOZ block arm chains. Water is a good solvent for both blocks, so that we may expect that both star block copolymers are molecularly dispersed in water. The scattering function for a molecularly dispersed Gaussian star block copolymer can be calculated by eqs S1-S5 in the Supporting Information. In Figure 6a, the solid curve for core-(PIPOZ- $b$-PEOZ) 4 at $25{ }^{\circ} \mathrm{C}$ indicates the $=$ theoretical values for the molecularly dispersed star block-copolymer with a main-chain bond length $b_{\mathrm{IPOZ}}=b_{\mathrm{EOZ}}=$ $0.41 \mathrm{~nm}$ for core-(PIPOZ- $b$-PEOZ) 4 . These $b$ values are smaller than the effective bond length estimated to be $0.67 \mathrm{~nm}\left[=(2 q h)^{1 / 2}\right]$ from the persistence length $q=0.7 \mathrm{~nm}^{19,20}$ and the contour length per monomer unit $h=0.32 \mathrm{~nm} .{ }^{21}$ The chain thickness effect on the scattering function may be one of reasons for the underestimate of the $b$ values in the fitting. ${ }^{22-24}$
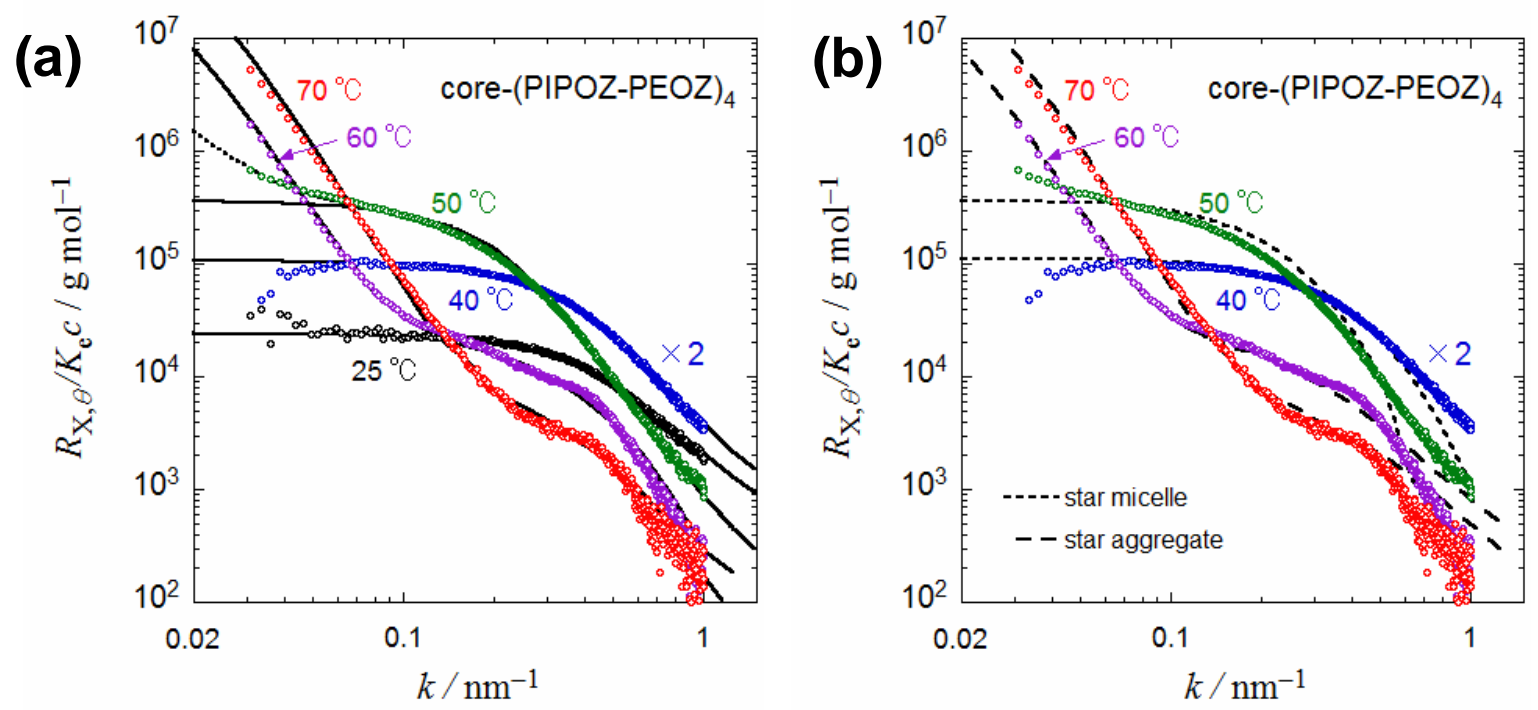

Figure 6. Comparison between theory (curves) and experiment (circles) for the scattering functions of aqueous core-(PIPOZ- $b$-PEOZ) 4 at different temperatures. Panel a shows the best fits, to be compared with less satisfactory fits shown in Panel b. Curves and circles at $40{ }^{\circ} \mathrm{C}$ are shifted vertically for viewing clarity.

In Panel a of Figure 5, the plateau value in the low $k$ region increases at 40 and $50{ }^{\circ} \mathrm{C}$, indicating that the isolated star-block copolymer chain aggregates to increase the molar mass 
or the aggregation number at 40 and $50{ }^{\circ} \mathrm{C}$. Because the PIPOZ block chain is more hydrophobic than the PEOZ block chain, we can expect for core-(PIPOZ- $b$-PEOZ) 4 to form the star aggregate or star micelle illustrated in Figure 7. Here, the star aggregate means the star polymer of which arm number is equal to the arm number of the original star multiplied by the aggregation number $m$, while the star micelle is the spherical micelle with the hydrophobic core of the uniform density formed by the inner hydrophobic block chains. The scattering functions for the star aggregate and star micelle are given by eqs S1-S5 where $f$ is replaced by $4 m$ and eqs S7-S9 in the Supporting Information, respectively.

(a) core-(PIPOZ-b-PEOZ) 4
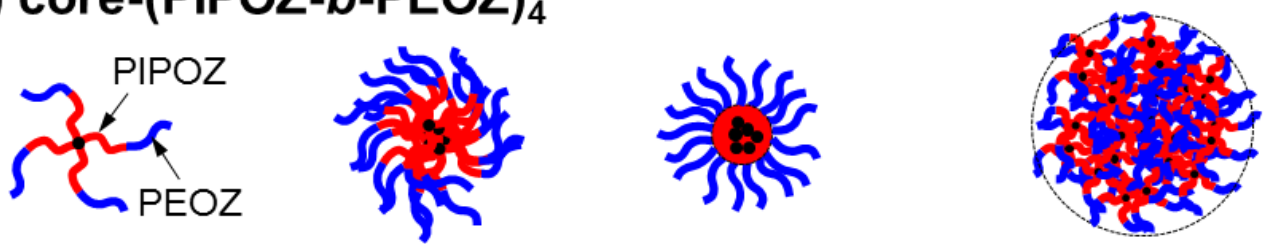

isolated chain star aggregate star micelle spherical aggregate

(b) core-(PEOZ-b-PIPOZ) 4

(concentrated-phase droplet)

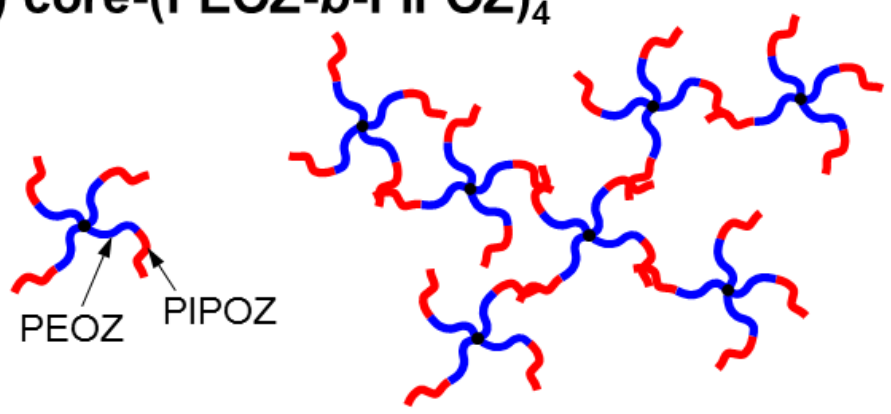

isolated chain

random aggregate

\section{spherical aggregate (concentrated-phase droplet)}

Figure 7. Schematic diagrams for different types of aggregates formed by star block-copolymers of core-(PIPOZ-b-PEOZ) 4 (a) and core-(PEOZ- $b$-PIPOZ) $)_{4}$ (b).

Solid curves for 40 and $50{ }^{\circ} \mathrm{C}$ in Figure 6a represent fitting results by the star aggregate model, calculated by eqs S1-S5. Agreements between theory and experiment are good at $k>$ $0.05 \mathrm{~nm}^{-1}$. As shown in Panel b of Figure 6, the star micelle model (using eqs S7-S9) gives 
the scattering functions at 40 and $50{ }^{\circ} \mathrm{C}$ decaying too rapidly at $k>0.5 \mathrm{~nm}^{-1}$ (dotted curves).

The SAXS scattering functions for core-(PIPOZ- $b$-PEOZ) $)_{4}$ at 60 and $70{ }^{\circ} \mathrm{C}$ shown in Figure 5a show strong upswings in the low $k$ region, that are less pronounced in the high $k$ region, indicating that large scattering component appears while the small scattering component gradually disappears. The scattering function for the solution containing the large and small scattering components may be written as ${ }^{13}$

$$
\frac{R_{\mathrm{X}, \theta}}{K_{\mathrm{e}} c}=M_{\mathrm{w}, 1}\left[w_{\mathrm{small}} m_{\mathrm{w}, \text { small }} P_{\text {small }}(k)+w_{\text {large }} m_{\mathrm{w}, \text { large }} P_{\text {large }}(k)\right]
$$

where $M_{\mathrm{w}, 1}$ is the molar mass of a single star block copolymer chain, $w_{\text {small }}, m_{\mathrm{w}, \text { small }}$ and $P_{\text {small }}(k)$ are the weight fraction (in the total copolymer), the weight-average aggregation number, and the particle scattering function of the small component, and $w_{\text {large, }}, m_{\mathrm{w}, \text { large }}$ and $P_{\text {large }}(k)$ are those of the large aggregated component. The scattering intensity of the large components is predominant only in low $k$ region, and that of the small component contributes mainly in high $k$ region, so that the parameters can be determined separately.

As shown in the previous subsection, macroscopic phase separation takes place in the aqueous solution of core-(PIPOZ-b-PEOZ) 4 at 50 and $60{ }^{\circ} \mathrm{C}$. Thus, the large aggregating component in the solution just after the T-jump to 60 and $70{ }^{\circ} \mathrm{C}$ must be colloidal droplets of the concentrated phase. The scattering function $P_{\text {sphere }}(k)$ for polydisperse spherical particles of uniform concentration $c_{\text {in }}$ given by eq S13 is used for $P_{\text {large }}(k)$ to fit the upswing scattering profiles at 60 and $70{ }^{\circ} \mathrm{C}$ in the low $k$ region. When the star micelle model is used for $P_{\text {small }}(k)$, we can fit the profiles at 60 and $70{ }^{\circ} \mathrm{C}$ over the entire $k$ region, as shown by solid curves in Figure $6 a$. The star aggregate model cannot fit the sharply decaying profiles at 60 and $70{ }^{\circ} \mathrm{C}$ at $k>0.5 \mathrm{~nm}^{-1}$, as indicated by dashed curves in Figure $6 \mathrm{~b}$.

Table 2. Values of fitting parameters for core-(PIPOZ- $b$-PEOZ) $)_{4}$ determined by SAXS profiles; $\left\langle S^{2}\right\rangle_{\mathrm{PIPOZ}}{ }^{1 / 2},\left\langle S^{2}\right\rangle_{\mathrm{PEOZ}}{ }^{1 / 2},\left\langle S^{2}\right\rangle_{\mathrm{star}}{ }^{1 / 2}$, and $\left\langle S^{2}\right\rangle_{\mathrm{Z}}$ are the radii of gyration of the PIPOZ and 
PEOZ block chains, of the star block copolymer chain, and of the spherical aggregate, respectively, and $R_{\text {core }}$ is the radius of the hydrophobic core of the star micelle (cf. the Supporting Information).

\begin{tabular}{|c|c|c|c|c|}
\hline Temperature & Component & $w$ & $m_{\mathrm{w}}$ & Remarks \\
\hline $25^{\circ} \mathrm{C}$ & isolated star & 1 & 1 & $\begin{array}{c}b_{\mathrm{IPOZ}}=b_{\mathrm{EOZ}}=0.41 \mathrm{~nm} \\
\left\langle S^{2}\right\rangle_{\mathrm{PIPOZ}}{ }^{1 / 2}=1.9 \mathrm{~nm},\left\langle S^{2}\right\rangle_{\mathrm{PEOZ}}{ }^{1 / 2}= \\
1.6 \mathrm{~nm},\left\langle S^{2}\right\rangle_{\mathrm{star}}{ }^{1 / 2}=4.0 \mathrm{~nm}\end{array}$ \\
\hline $40{ }^{\circ} \mathrm{C}$ & star aggregate & 1 & 2.2 & $\begin{array}{c}b_{\mathrm{IPOZ}}=b_{\mathrm{EOZ}}=0.48 \mathrm{~nm} \\
\left\langle S^{2}\right\rangle_{\mathrm{PIPOZ}}{ }^{1 / 2}=2.3 \mathrm{~nm},\left\langle S^{2}\right\rangle_{\mathrm{PEOZ}^{1 / 2}}= \\
1.9 \mathrm{~nm},\left\langle S^{2}\right\rangle_{\mathrm{star}}^{1 / 2}=4.9 \mathrm{~nm}\end{array}$ \\
\hline \multirow[b]{2}{*}{$50^{\circ} \mathrm{C}$} & star aggregate & 0.993 & 15 & $\begin{array}{c}b_{\mathrm{IPOZ}}=b_{\mathrm{EOZ}}=0.87 \mathrm{~nm} \\
\left\langle S^{2}\right\rangle_{\mathrm{PIPOZ}}{ }^{1 / 2}=4.1 \mathrm{~nm},\left\langle S^{2}\right\rangle_{\mathrm{PEOZ}}{ }^{1 / 2}= \\
3.4 \mathrm{~nm},\left\langle S^{2}\right\rangle_{\mathrm{star}}{ }^{1 / 2}=9.2 \mathrm{~nm}\end{array}$ \\
\hline & spherical aggregate & 0.007 & $5.0 \times 10^{4}$ & $\begin{array}{c}m_{\mathrm{w}, \mathrm{small}} / m_{\mathrm{n}, \mathrm{small}}=20 \\
c_{\mathrm{in}}=0.24 \mathrm{~g} / \mathrm{cm}^{3},\left\langle S^{2}\right\rangle_{\mathrm{z}}=220 \mathrm{~nm}\end{array}$ \\
\hline \multirow[t]{2}{*}{$60{ }^{\circ} \mathrm{C}$} & star micelle & 0.43 & 2 & $\begin{array}{c}c_{\text {core }}=0.18 \mathrm{~g} / \mathrm{cm}^{3}, R_{\text {core }}=4.0 \mathrm{~nm} \\
b_{\mathrm{EOZ}}=0.47 \mathrm{~nm}\end{array}$ \\
\hline & spherical aggregate & 0.57 & $3.0 \times 10^{5}$ & $\begin{array}{c}m_{\mathrm{w}, \mathrm{small}} / m_{\mathrm{n}, \mathrm{small}}=30 \\
c_{\mathrm{in}}=0.04 \mathrm{~g} / \mathrm{cm}^{3},\left\langle S^{2}\right\rangle_{\mathrm{z}}=830 \mathrm{~nm}\end{array}$ \\
\hline \multirow{2}{*}{$70{ }^{\circ} \mathrm{C}$} & star micelle & 0.09 & 2 & $\begin{array}{c}c_{\text {core }}=0.35 \mathrm{~g} / \mathrm{cm}^{3}, R_{\text {core }}=3.2 \mathrm{~nm} \\
b_{\mathrm{EOZ}}=0.30 \mathrm{~nm}\end{array}$ \\
\hline & spherical aggregate & 0.91 & $1.5 \times 10^{5}$ & $\begin{array}{c}m_{\mathrm{w}, \mathrm{smal}} / m_{\mathrm{n}, \mathrm{small}}=100 \\
c_{\mathrm{in}}=0.042 \mathrm{~g} / \mathrm{cm}^{3},\left\langle S^{2}\right\rangle_{\mathrm{z}}=900 \mathrm{~nm}\end{array}$ \\
\hline
\end{tabular}

The scattering profile for core-(PIPOZ- $b$-PEOZ) 4 at $50{ }^{\circ} \mathrm{C}$ in Figure 6 a has also a weak upswing in the low $k$ region. As indicated by the dotted curve in Figure 6a, the addition of a 
tiny amount of colloidal droplets of the concentrated phase to the star aggregate model fits better in the low $k$ region. Fitting parameters used for the profiles of aqueous core-(PIPOZ- $b$-PEOZ) $)_{4}$ at different temperatures are summarized in Table 2.

Scattering profiles for the aqueous solution of core-(PEOZ- $b$-PIPOZ) $)_{4}$ at different temperatures shown in Figure $5 \mathrm{~b}$ are fitted similarly. The solid curve at $25{ }^{\circ} \mathrm{C}$ in Figure 8 indicates the fitting result by the molecularly dispersed star block-copolymer with the main-chain bond lengths $b_{\mathrm{IPOZ}}=b_{\mathrm{EOZ}}=0.43 \mathrm{~nm}$ for core-(PEOZ- $b$-PIPOZ $)_{4}$. The upswing of the experimental scattering function at $k<0.1 \mathrm{~nm}^{-1}$ at $25^{\circ} \mathrm{C}$ indicates the contamination of a tiny amount of a large aggregate. Because the dehydration does not take place at $25{ }^{\circ} \mathrm{C}$ on the core-(PEOZ- $b$-PIPOZ) $)_{4}$ chain, the large aggregate may not be the concentrated phase droplet but a random aggregate of the star block copolymer illustrated in Figure $7 \mathrm{~b}$. The dotted curve for $25{ }^{\circ} \mathrm{C}$ in Figure 8 shows the fitting result by the model of a mixture of the isolated chain and random aggregate, using eq 5 along with eqs S10 and S11 in the Supporting Information. The weight fraction of the random aggregate is only $0.15 \mathrm{wt} \%$, but the aggregation number is as high as $1.3 \times 10^{5}$, so that the scattering power of the aggregate is very strong. Similar enhanced low angle scattering was observed in dilute solutions of thermosensitive linear homopolymers and block copolymers in good solvents, ${ }^{25,26}$ although the reason for the large aggregate formation in good solvents remains to be seen. 


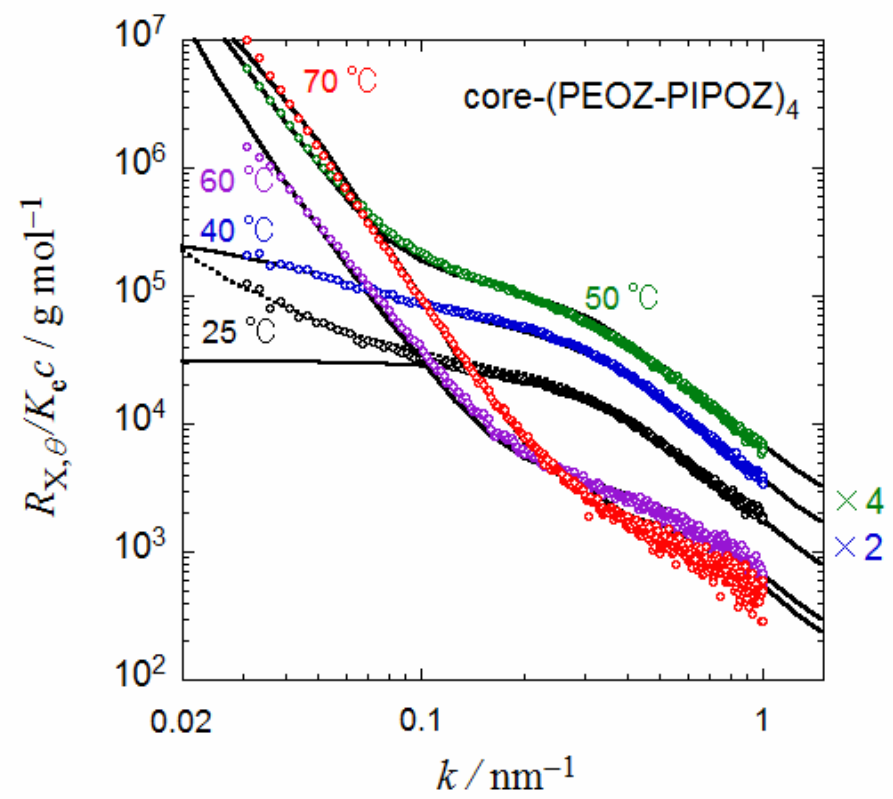

Figure 8. Comparison between theory (curves) and experiment (circles) for the scattering functions of aqueous core-(PEOZ- $b$-PIPOZ) 4 at different temperatures. Curves and circles at 40 and $50{ }^{\circ} \mathrm{C}$ are shifted vertically for viewing clarity.

The scattering profile at $40{ }^{\circ} \mathrm{C}$ can be fitted by the same mixture model of the isolated chain and random aggregate, although the aggregation number of the random aggregate $(=1.3$ $\times 10^{3}$ ) is much smaller than that at $25^{\circ} \mathrm{C}$. The upswing of the scattering profiles at $50-70{ }^{\circ} \mathrm{C}$ may be attributed to colloidal droplets of the concentrated phase, as in the case of core-(PIPOZ- $b$-PEOZ) 4 . To the small scattering component, we can assign the isolated star over all temperatures examined, although the aggregation number only at $50{ }^{\circ} \mathrm{C}$ should be chosen to be slightly larger than unity $(=1.25)$. The good fitting results are shown by solid curves in Figure 8, and the fitting parameters determined are listed in Table 3. The monomer unit lengths $b_{\mathrm{EOZ}}$ and $b_{\mathrm{IPOZ}}$ at 60 and $70{ }^{\circ} \mathrm{C}$ are considerably smaller than the expected $(=0.67$ $\mathrm{nm}$; see above), which may reflect the shrinkage of the copolymer chain due to dehydration (cf. Figure 2). 
Table 3. Values of fitting parameters for core-(PEOZ- $b$-PIPOZ) 4 determined by SAXS profiles; $\left\langle S^{2}\right\rangle_{\mathrm{PIPOZ}}{ }^{1 / 2},\left\langle S^{2}\right\rangle_{\mathrm{PEOZ}}{ }^{1 / 2},\left\langle S^{2}\right\rangle_{\mathrm{star}}{ }^{1 / 2}$, and $\left\langle S^{2}\right\rangle_{\mathrm{Z}}$ are the radii of gyration of the PIPOZ and PEOZ block chains, of the star block copolymer chain, and of the spherical aggregate, respectively, and $R_{\text {core }}$ is the radius of the hydrophobic core of the star micelle (cf. the Supporting Information).

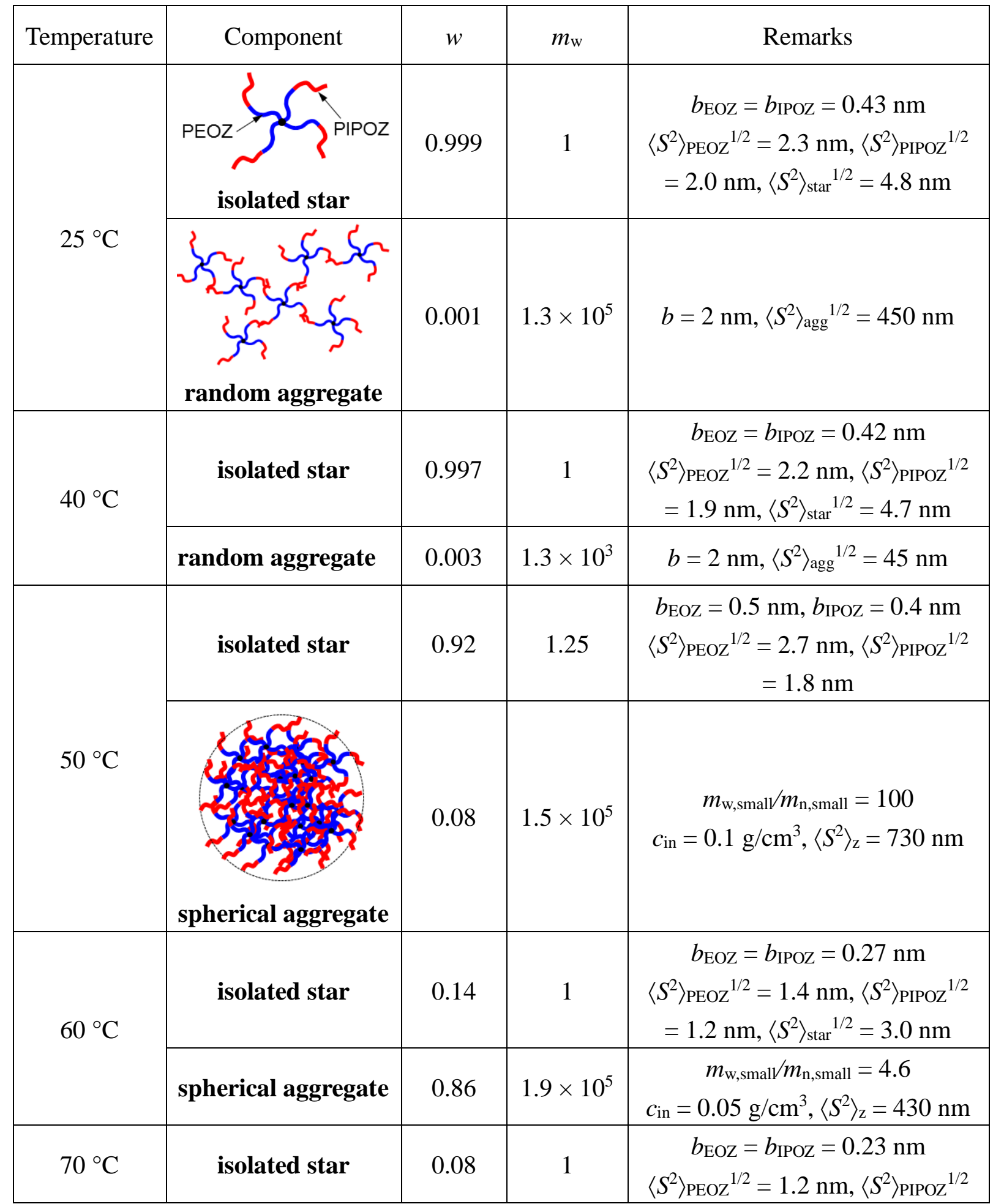




\begin{tabular}{|c|c|c|c|c|}
\hline & & & $=1.0 \mathrm{~nm},\left\langle S^{2}\right\rangle_{\mathrm{star}}{ }^{1 / 2}=2.5 \mathrm{~nm}$ \\
\cline { 2 - 4 } & spherical aggregate & 0.92 & $5.0 \times 10^{3}$ & $\begin{array}{c}m_{\mathrm{w}, \mathrm{smal}} / m_{\mathrm{n}, \mathrm{small}}=20 \\
c_{\text {in }}=0.04 \mathrm{~g} / \mathrm{cm}^{3},\left\langle S^{2}\right\rangle_{\mathrm{z}}=210 \mathrm{~nm}\end{array}$ \\
\hline
\end{tabular}

\section{CONCLUSIONS}

The dependence on molecular architecture of the dehydration, phase separation, and micellization behavior were investigated for aqueous solutions of thermosensitive polyoxazoline star block copolymers. Two star block copolymers, core-(PIPOZ-b-PEOZ) 4 and core-(PEOZ- $b$-PIPOZ) 4 , where more hydrophobic PIPOZ block chains are inside and outside the star block copolymer respectively, were synthesized, and their dilute aqueous solutions were examined by HS-DSC, turbidity, and SAXS measurements. The dehydration and phase separation behavior is not so much different for the two star block copolymers with opposite am architecture. However, the micellization behavior is remarkably different for the two star block copolymers. The PIPOZ blocks inside core-(PIPOZ- $b$-PEOZ) 4 trigger the formation of the star micelles in water upon heating. However, core-(PEOZ- $b$-PIPOZ) $)_{4}$ exists as the isolated chains in water even at high temperatures, possibly because the collapsed PIPOZ blocks on the periphery of the star remain separated from each other by PEOZ loops and cannot aggregate.

\section{ACKNOWLEDGEMENT}

The synchrotron radiation experiments were performed at the BL40B2 in SPring-8 with the approval of the Japan Synchrotron Radiation Research Institute (JASRI) (Proposal No 2017B1409). We thank Dr. K. Terao at Osaka University for helping with the SAXS measurements. This work was supported in part by JSPS KAKENHI Grant No. 18H02020.

\section{REFERENCES}

1. Ren, J. M.; McKenzie, T. G.; Fu, Q.; Wong, E. H. H.; Xu, J.; An, Z.; Shanmugam, S.; 
Davis, T. P.; Boyer, C.; Qiao, G. G. Chem. Rev. 2016, 116, 6743-6836.

2. Qiu, N.; Li, Y.; Li, Y.; Wang, H.; Duan, Q.; Kakuchi, T. RSC Adv. 2016, 6, 47912-47918.

3. Takamizu, K.; Nomura, K. J. Am. Chem. Soc. 2012, 134, 7892-7895.

4. Libera, M.; Trzebicka, B.; Kowalczuk, A.; Wałach, W.; Dworak, A. Polymer 2011, 52, $250-257$.

5. Qu, Y.; Chang, X.; Chen, S.; Zhang, W. Polym. Chem. 2017, 8, 3485-3496.

6. Zhou, J.; Wang, L.; Ma, J.; Wang, J.; Yu, H.; Xiao, A. European Polym. J. 2010, 46, $1288-1298$

7. Sánchez-Bustos, E.; Cornejo-Bravo, J.; Licea-Claverie, A. J. Chem. 2016, 2016, 4543191.

8. Tao, K.; Wang, Y.; Wang, W.; Lu, D.; Wang, Y.; Bai, R. Macromol. Chem. Phys. 2009, $210,478-485$.

9. Strandman, S.; Zarembo, A.; Darinskii, A. A.; Laurinmäki, P.; Butcher, S. J.; Vuorimaa, E.; Lemmetyinen, H.; Tenhu, H. Macromolecules 2008, 41, 8855-8864.

10. Hu, H.; Liu, G. Macromolecules 2014, 47, 5096-5103.

11. Tasci, E.; Aydin, M.; Gorur, M.; Gürek, A. G.; Yilmaz, F. J. PAppl. Polym. Sci. 2018, 135, 46310.

12. Bekhradnia, S.; Diget, J. S.; Zinn, T.; Zhu, K.; Sande, S. A.; Nyström, B.; Lund, R. Macromolecules 2015, 48, 2637-2646.

13. Takahashi, R.; Sato, T.; Terao, K.; Qiu, X.-P.; Winnik, F. M. Macromolecules 2012, 45, $6111-6119$

14. Huber, S.; Jordan, R. Colloid Polym. Sci. 2008, 286, 395-402.

15. Fijten, M. W. M.; Haensch, C.; van Lankvelt, B. M.; Hoogenboom, R.; Schubert, U. S. Macromol. Chem. Phys. 2008, 209, 1887-1895.

16. Takahashi, R.; Sato, T.; Terao, K.; Yusa, S. Macromolecules 2015, 48, (19), 7222-7229.

17. Takahashi, R.; Sato, T.; Terao, K.; Yusa, S. Macromolecules 2016, 49, (8), 3091-3099. 
18. Takahashi, R.; Qiu, X.-P.; Xue, N.; Sato, T.; Terao, K.; Winnik, F. M. Macromolecules 2014, 47, 6900-6910

19. Sung, J. H.; Lee, D. C. Polymer 2001, 42, 5771-5779.

20. Kondo, M.; Takahashi, R.; Qiu, X.-P.; Winnik, F. M.; Terao, K.; Sato, T. Polym. J. 2016, submitted.

21. Litt, A.; Rahl, F.; Roldan, L. G. J. Polym.Sci.: Part A2 1969, 7, 463-473.

22. Hickl, P.; Ballauff, M.; Scherf, U.; Müllen, K.; Lindner, P. Macromolecules 1997, 30, (2), 273-279.

23. Terao, T.; Mizuno, K.; Murashima, M.; Kita, Y.; Hongo, C.; Okuyama, K.; Norisuye, T.; Bächinger, H. P. Macromolecules 2008, 41, (19), 7203-7210.

24. Arakawa, S.; Terao, K.; Kitamura, S.; Sato, T. Polym. Chem. 2012, 3, 472-478.

25. Kawaguchi, T.; Kobayashi, K.; Osa, M.; Yoshizaki, T. J. Phys. Chem. B 2009, 113, $5440-5447$

26. Sato, T.; Tanaka, K.; Toyokura, A.; Mori, R.; Takahashi, R.; Terao, K.; Yusa, S. Macromolecules 2013, 46, 226-235. 
Table of Contents Graphic

"Dehydration, Micellization, and Phase Separation of Thermosensitive Polyoxazoline Star Block-Copolymers in Aqueous Solution" by Tetiana Sezonenko, Xing-Ping Qiu, Françoise M. Winnik, and Takahiro Sato

\begin{tabular}{|c|c|c|}
\hline Temp. & core-(PIPOZ-b-PEOZ) ${ }_{4}$ & core-(PEOZ-b-PIPOZ) ${ }_{4}$ \\
\hline \multicolumn{3}{|l|}{$25^{\circ} \mathrm{C}$} \\
\hline \multicolumn{3}{|l|}{$50^{\circ} \mathrm{C}$} \\
\hline $60^{\circ} \mathrm{C}$ & & \\
\hline $10^{\circ} \mathrm{C}$ & 5 & \\
\hline
\end{tabular}

